\title{
Vivências de Ercília Nogueira Cobra em Caxias do Sul: sob o prisma de registros históricos*
}

\author{
Kátia Cardoso Nostrane ** \\ Cecil Jeanine Albert Zinani***
}

\begin{abstract}
Resumo
O artigo "Vivências de Erćlia Nogueira Cobra em Caxias do Sul sob o prisma de registros históricos" objetiva investigar a trajetória da escritora paulista na cidade de Caxias do Sul, no Rio Grande do Sul, na década de 1930. Para tanto, utilizam-se, como subsídio da pesquisa, registros documentais e históricos. Dentre eles, destacam-se dois processos judiciais, requerimentos enviados por Cobra à Prefeitura da cidade, bem como, publicações na imprensa caxiense, nas quais a autora foi citada. Dessa forma, este estudo busca evidenciar as possíveis relações entre Cobra e a sociedade caxiense.
\end{abstract}

Palavras-chave: Ercília Nogueira Cobra, Caxias do Sul, Registros Documentais.

* Recebido em 08 de março de 2019, aceito em 31 de julho de 2020.

* Graduanda em Psicologia e Bolsista de Iniciação Científica Universidade de Caxias do Sul, Caxias do Sul, RS, Brasil. nostranek@gmail.com/ https://orcid.org/0000-0003-1515-7521

*** Professora titular e pesquisadora nos Programas de Pós-Graduação em Letras e Cultura e no Curso de Letras, Universidade de Caxias do Sul, Caxias do Sul, RS, Brasil. cezinani@terra.com.br / https://orcid.org/0000-0002-8656-8865 
Experiences of Ercília Nogueira Cobra in Caxias do Sul: through the Lens of Historical Records

\begin{abstract}
The article "Experiences of Ercilia Nogueira Cobra in Caxias do Sul: through the lens of historical records" investigates Ercília Nogueira Cobra, a Brazilian writer born in São Paulo, during her stay in the city of Caxias do Sul, Rio Grande do Sul state, in the 1930s. It is based on historical documents and other records. They are highlighted by two legal proceedings Cobra filed with the municipal government and articles from the local press that mention the writer. The study reveals possible relations between Cobra and the Caxias do Sul community during that period.
\end{abstract}

Keywords: Ercília Nogueira Cobra, Caxias do Sul, Documentary Records. 
A tese que defendo é a seguinte: noventa por cento das mulheres que estão nos prostíbulos aí não caíram por vício, mas por necessidade. Se os pais dessas desgraçadas em vez de as obrigarem a guardar uma virgindade contrária às leis da natureza lhes tivessem dado uma profissão com a qual elas pudessem viver honestamente, elas ali não estariam (Ercília Nogueira Cobra).

\section{Considerações iniciais}

A epígrafe acima foi escrita por Ercília Nogueira Cobra, no prefácio de seu livro Virgindade anti-higiênica: preconceitos e convenções hipócritas (1924), o qual foi apreendido, por conter teor pornográfico. A autora, que nasceu no ano de 1891, em Mococa, interior de São Paulo, também escreveu Virgindade inútil: novela de uma revoltada (1927). Ambas as obras causaram grande impacto na sociedade brasileira do início do século XX, por abordarem questões de caráter feminista. Em seus livros, Cobra critica as convenções morais que atuam sobre o comportamento da mulher, principalmente no que diz respeito à inibição da sexualidade feminina, e defende o direito de a mulher alcançar seu espaço na sociedade por meio do trabalho. Para isso, a autora defende a educação para as mulheres.

Em 1980, a partir da intensificação dos estudos de gênero na literatura, e também com a publicação do trabalho de Maria Lúcia de Barros Mott, no ano 1986, intitulado Biografia de uma revoltada: Ercília Nogueira Cobra, a história dessa autora começa a ser resgatada. Mott (1986), por meio do relato de familiares e conhecidos de Cobra, relata sua trajetória em São Paulo. E, por meio de entrevistas e troca de cartas, traz algumas informações sobre a passagem da autora pela cidade de Caxias do Sul, no estado do Rio Grande do Sul.

De modo semelhante, o presente trabalho objetiva investigar a trajetória de Ercília Nogueira Cobra em Caxias do Sul, nos anos em que a autora viveu na cidade, e evidenciar suas possíveis relações com o município. Para tanto, utilizam-se, como aporte da pesquisa, registros documentais $e$ históricos da cidade caxiense, dentre eles, dois processos judiciais que envolveram a autora na década de 1930. Tais processos encontram-se no Instituto Memória Histórica e Cultural (IMHC), da Universidade de Caxias do Sul. A utilização dos referentes documentos foi autorizada, para fins acadêmicos de pesquisa, pelo Juiz da $1^{\text {a }}$ Vara Cível da Comarca de Caxias, devido Cobra ser uma figura pública. Além disso, há os requerimentos que Cobra enviou à Prefeitura Municipal, que estão disponíveis no Arquivo Histórico Municipal João Spadari Adami. E, por fim, são utilizadas também as publicações da imprensa local, de acesso público, por meio do site da Câmara Municipal de Caxias do Sul e da Biblioteca Nacional.

\section{Mulheres na Cidade de Caxias do Sul (1930)}

Caxias do Sul, no Rio Grande do Sul, é uma cidade fundada em 1875, por imigrantes vindos do norte da Itália. No início do século XX, a cidade passou por um movimento migratório das zonas rurais para o grande centro urbano. Em 1930, houve um grande crescimento da indústria metalúrgica, em virtude, principalmente, da Primeira Guerra Mundial, que acelerou o processo de industrialização após obrigar as indústrias a fabricarem máquinas e peças que vinham do exterior. (Machado, 1998). Com isso, é recorrente a presença de mulheres dentro das fábricas, adquirindo trabalho feminino uma relevante importância no cenário econômico local, devido às novas demandas da época (Favaro, 1996).

A posição atribuída à mulher caxiense correspondia a um papel secundário, no qual obediência e submissão à autoridade masculina prevaleciam. De acordo com Maria Abel Machado (1998), há uma divisão sexual, tida como natural, dos papéis familiares; o pai era o chefe, e a família deveria submeter-se a ele. Essa realidade também era refletida no trabalho das fábricas, já que, conforme aponta Machado (1998), o salário da mulher era menor que o do homem, pois considerava-se o salário feminino apenas "complementar" ao do marido, visto que ele era o provedor da casa e da família. Nas palavras de Margareth Rago (1997:65): 
em qualquer caso, o campo de atuação da mulher fora do lar circunscreveu-se ao de ajudante, assistente, ou seja, uma função de subordinação a um chefe masculino em atividades que a colocaram desde sempre à margem de qualquer processo decisório.

No interior das fábricas, as mulheres ocuparam posições consideradas inferiores e de menor status. Isso, de acordo com Valentim Lazzarotto (1981), acontecia não apenas devido às políticas das empresas, mas também à passividade e acomodação das funcionárias. Além disso, a discriminação, a inferioridade e a submissão estavam presentes tanto no espaço doméstico quanto dentro das fábricas. E, conforme Cleci Favaro (1996), tal condição subalterna permaneceu inalterada na cidade até meados da década de 1950.

Embora houvesse uma maior apropriação do espaço público pelas mulheres, isso não significou um "abrandamento das exigências morais" (Rago, 1997:63). O discurso moralista estava presente, principalmente, pelos enunciados religiosos da Igreja Católica. Devido à forte cultura católica na Itália dos séculos XVIII e XIX, em que a Igreja disseminou ideais acerca de ser "esposa e mãe", estabeleceram-se significativamente esses preceitos nas Regiões de Colonização Italiana (RCI). (Dotti, 2007). Nesse sentido, uma vez que, de acordo com Gabriela Michelon Dotti (2007:99), "a mulher é transformada no principal sustentáculo do catolicismo", cria-se aquilo que Sandra Da Canal e Thaís Wenczenovicz (2012) chamam de mecanismos moralizantes de controle. Tais mecanismos operam numa tentativa de preservar uma conduta feminina adequada a padrões de comportamentos da época, consequentemente, ligada à moral. Dessa forma, constitui-se a família patriarcal regida pelos princípios religiosos.

Em contrapartida a essas imposições sociais e morais, a mulher caxiense tinha maior autonomia na sociedade em duas situações: a primeira, quando havia uma oportunidade de mudar sua situação, seja pela viuvez ou pelo abandono, em que continuava e mantinha o negócio da família, muitas vezes, retornando ao nome de solteira (Machado, 1998); ou, por outro lado, quando se tornava proprietária de bordel, uma vez que, nesse ramo, havia um grande número de mulheres. (Matté, 2008).

Caxias do Sul, nesse período, conforme Aline Matté (2008), contava com uma grande quantidade de cabarés na região central, conhecida como a zona do meretrício. De acordo com Loraine Giron (1999), os bordéis eram conhecidos como "pensões não-familiares", sendo inseridos nos Livros dos Impostos a partir de 1920. Logo, a grande incidência da prostituição que estava presente na $\mathrm{RCI}$ desde o ano de 1910 (Matté, 2008) apresenta uma contradição com leis morais presentes nas famílias, visto que a existência de tais locais dependia, sobretudo, de frequentadores. Nesse sentido, Daysi Lange (2012) reflete sobre a discrepância entre o modelo social idealizado imposto para as mulheres e a aparição de mulheres com atitudes diferentes daquelas que a sociedade caxiense queria transmitir.

É nesse cenário que Cobra estabeleceu-se na cidade. De acordo com Mott (1986), ela se mudou para Caxias no ano de 1934, aos 43 anos de idade. Ao chegar à cidade abriu um cabaré que recebeu o nome de "Pensão Royal", localizado na rua Bento Gonçalves, n ${ }^{\circ} 1670^{1}$, onde era conhecida como Suzy Germano.

Os relatos encontrados por Mott (1986) descrevem-na como pianista e culta, sempre muito elegante, usando um tailleur escuro com um chapéu de feltro. Assim, em todas as tardes, sentava-se à praça para ler algum jornal ou revista. Mulher conhecida por ser temperamental, pois "[...] quando não tinha movimento ela ficava batendo no teclado do piano e punha todo mundo para fora [...], em outra ocasião, faltando fregueses, subiu no sótão e gritou - fogo! - juntando assim uma multidão [...]." (Mott, 1986:98). Dessa maneira, Cobra conseguia chamar atenção e atrair clientes para sua casa.

\footnotetext{
1 Em alguns documentos consta que o número da casa era 1760.
} 


\section{Ercília Nogueira Cobra: vida, obra e vivências}

Em meados de 1980, (re)descobre-se uma autora que até então fora silenciada e esquecida pelos estudiosos de literatura: Ercília Nogueira Cobra. Esse momento inicia com tímidas menções a seu nome e suas obras, porém, é em 1986 que Cobra começa a ganhar voz e espaço na historiografia, por meio da biografia escrita por Mott.

A partir de Mott (1986), sabe-se que Ercília era a segunda irmã mais velha de uma família de seis irmãos. A família, que era abastada, perdeu tudo após a morte do avô materno, o qual mantinha os bens da família. Seu pai, Amador Brandão Nogueira Cobra, morre, um tempo depois, deixando a família sem recursos. Desde então, Ercília e a irmã mais velha, Estela, viveram confinadas em uma fazenda com a mãe. Até que, em meados do ano de 1909, Ercília e Estela fogem da fazenda, sendo recolhidas no Asilo Bom Pastor, o qual existia com o propósito de educar meninas pobres, saindo de lá quatro meses depois. Ainda longe de casa, Ercília ingressa na Escola Normal Primária. Cobra parecia bastante revoltada, uma vez que provocava tumultos em sala de aula, além de assustar as colegas quando discutia com as professoras. Prestou concurso para professora, mas nunca chegou a exercer a função.

A partir de 1929, a relação com a família, principalmente com o irmão, tornou-se complicada. As próximas notícias da autora datam 1934, período em que morou na cidade de Caxias do Sul, no Rio Grande do Sul. Após esse período, conforme entrevista realizada com D. Maria Custódia (Mott, 1986), uma parente dos Nogueira Cobra, Ercilia teria sido presa pelo Estado Novo em São Paulo, Paraná, Rio de Janeiro e Rio Grande do Sul. De acordo com essa parente, a autora havia sofrido maus tratos, sendo interrogada e torturada sempre nua. No entanto, o interrogatório não girava em torno de opiniões políticas, mas sim acerca de sua percepção sobre o universo masculino. Isso pois,

[...] os homens estavam muito machucados com a opinião dela (...) a visão que eles tinham é que ela era uma ameaça tremenda. Porque se ela levantasse as mulheres daquela época, eles tinham a impressão que iam derrubar o regime (Mott, 1986:99).

Em seguida, a autora teria sido detida no presídio Maria Zélia, conhecido por prender pessoas consideradas comunistas. A última notícia que se tem é que ela teria trocado de nome e fugido para o Paraná. Até hoje não se sabe como nem onde Ercília morreu.

Enquanto escritora, Cobra transgride os limites estabelecidos às mulheres do início do século $\mathrm{XX}$. Inicialmente, com a produção de suas obras em um contexto em que a literatura não era de fácil acesso ao universo feminino, e, depois, com o conteúdo trazido em seus livros, nos quais, com uma linguagem "nua e crua", revela uma sociedade que subjuga as mulheres. Sua primeira obra foi Virgindade anti-hygiênica: preconceitos e convenções hipócritas, publicada em 1924, pela editora de Monteiro Lobato, a qual, logo após, teve sua circulação proibida, pois foi considerada pornográfica. Virgindade inútil: novela de uma revoltada, publicada em 1927, foi sua segunda e última obra. No ano de 1932, o ensaio e a novela foram reunidos em um só livro intitulado Virgindade inútil e anti-hygienica. Houve, também, uma publicação dessa última em Paris, pela editora Societé d'Éditions Oeuvres des Maitres Celèbre, sem data. Mais tarde, no ano de 1937, há a menção em uma das cartas enviadas à irmã sobre a próxima obra, que se chamaria $O$ filho da mãe. (Mott, 1986). Tal obra nunca chegou ao público leitor.

É inegável que seus escritos trazem à tona a realidade da mulher brasileira do início do século do XX, representando, por meio de seus personagens, mulheres cujos papéis sociais não correspondiam àquele esperado pelo imaginário social da época. Cobra dá voz ao sofrimento daquelas que Danielle Sousa (2016) denomina mulher marginal, mulher difícil, mulher prostituta e mulher suicida. Caberia aqui mais uma definição: mulher emancipada, que representa a categoria que não se inclui no discurso dominante sobre o feminino, cujo comportamento é inadmissível pela sociedade conservadora, que a marginaliza e, sobretudo, a silencia. Ercília Nogueira Cobra resgata esse sofrimento, e, por meio de uma literatura na qual se permite falar o não falado, utilizando críticas sociais e morais, torna visível a existência dessas mulheres.

Sousa (2016) aponta que Cobra escreveu seus livros com o propósito de romper com a idealização do feminino no início do século XX. Ao apresentar outra representação à mulher 
moderna, permite o questionamento do status quo tanto pelos leitores quanto pelas leitoras. De acordo com Sousa (2016), esse pode ter sido o real motivo da proibição de suas obras, e não apenas devido ao teor "pornográfico".

Investigar fontes documentais e históricas de uma cidade significa percorrer, por meio de discursos, histórias que nem sempre são contadas. Tais histórias permitem o conhecimento de uma sociedade por meio das atitudes daquelas cujas narrativas estão nos arquivos. Com isso, os processos judiciais configuram uma parte da história que possibilita o estudo dos fatores circundantes da esfera social, bem como o resgate de figuras importantes, e frequentemente, esquecidas, como é o caso de Ercília Nogueira Cobra.

$\mathrm{O}$ IMHC, que tem como objetivo preservar materiais documentais de cunho histórico e cultural da instituição (UCS) e da região (RCI), abrindo espaço para o campo da pesquisa ao disponibilizar materiais como fonte de consulta. Assim, possibilita, segundo Luiza Iotti e Fabrício Gomes (2012), a (re)construção da história da cidade caxiense. Com isso, também traz à tona a uma parte das vivências de Ercília, a qual é tampouco lembrada pelos moradores da cidade.

Um dos processos encontrados refere-se a uma denúncia feita contra Cobra a respeito dos escândalos que aconteciam na Pensão Royal, bordel pertencente à autora. Essa queixa aconteceu no dia 05 de março de 1938, na qual, segundo o relatório do promotor, o denunciante solicitava "investigações devidas para o esclarecimento de fatos que depoem contra a moral e bons costumes, praticados na Pensão Royal, de propriedade da decaída Ercília Nogueira, mais conhecida por 'Suzi'”2 (CMRJU/IMHC/UCS. Indagações Policiais. Processo $n^{\circ} 17$, caixa $n^{\circ} 2 C: 3.1938$ ). Isso deu início ao Processo n ${ }^{\circ} 207$ de $1938^{3}$.

No relatório do promotor, é possível observar o uso de palavras de cunho depreciativo ao referenciar tanto o cabaré quanto a autora. Em várias citações, a Pensão Royal é mencionada como um antro de perdição, imoralidade e promiscuidade, e Ercília é referida como decaída e desavergonhada. Toda essa situação é vista pela promotoria e pelo denunciante como um prejuízo moral às famílias e, principalmente, às moças que viviam ali perto, pois estariam, constantemente, constrangidas com as "cenas imorais" vistas através das janelas do cabaré, e pelos palavrões impróprios pronunciados por elas, em altos brados.

De certa forma, o que se percebe ao longo do processo é o conflito existente entre o discurso moralizador $e$ a posição dessas mulheres em seguir aquilo que lhes é socialmente destinado. Se, por um lado, elas não correspondem ao ideal de boas esposas e mães, por outro, retratam "mulheres de má vida, meretrizes insubmissas, impuras e insignificantes" (Rago, 1997:85), aos olhos da sociedade. Assim, nota-se uma incompreensão da sociedade em relação às mulheres que

[...] recusam o aconchego do casamento, que negam a importância do lar e preferem circular enfeitadas pelas ruas, desnudando partes íntimas do corpo, exaltando perfumes fortes $e$ extravagantes, provocando tumultos e escândalos, subversivas que rejeitam o mundo edificante do trabalho, surdas ao discurso masculino moralizante [...] (Rago, 1997:85).

É interessante a forma como, em 10 de março de 1938, Ercília Nogueira Cobra responde à denúncia em seu depoimento:

Quanto ao facto de que a declarante mercadeja infelizes decaídas, não é exacto em vista de que as mulheres que ali residem não pagam pensão, somente dansam a noite. Durante as horas de dansas as mulheres não podem sahir do salão, sendo consideradas como bailarinas e não como prostitutas; quanto a embriaguez a alegação não é verdadeira disse a declarante porque a cerveja que é vendida não dá para embriagar-se; quanto as palavras pornográphicas não é de admirar que ellas sejam pronunciadas por operários frequentadores do cabaret, quando os próprios expuentes da sociedade caxiense as pronunciam na praça dante. Essas senhoras e essas moças deveriam se escandalizar mais das fitas que são passadas mensalmente nos cinemas (CMRJU/IMHC/UCS. Indagações Policiais. Processo no 17, caixa n 2C:8. 1938).

\footnotetext{
2 Todas as citações dos processos judiciais foram transcritas em sua forma original.

3 CMRJU/IMHC/UCS. Indagações Policiais. Processo nº 17, caixa n 2C. 1938.
} 
Essa resposta, juntamente com outras de Cobra, pode ter induzido o promotor a escrever no relatório sobre a indiferença e o seu "pouco caso" às reclamações. Coincidindo com as palavras do denunciante, nas quais Ercília teria se revelado verdadeiramente uma megera, ao apoiar-se no direito da propriedade privada, afrontando "audaciosamente, uma sociedade inteira, já empregando o brocardo: 'os incomodados que se mudem'" (CMRJU/IMHC/UCS. Indagações Policiais. Processo $n^{\circ} 17$, caixa $n^{\circ} 2 \mathrm{C}: 4$ 1938). As atitudes de Cobra, que foram repudiadas por ir de encontro às condutas femininas da época, revelam o oposto da mulher socialmente aceita $e$ valorizada, daquela que sabe o seu lugar e representa o seu papel social e sexual (Favaro, 1996).

Outro dado que contribui com tal percepção é o documento redigido pela Coletoria do Estado, a pedido do denunciante, em virtude de acusações feitas por Cobra ao Secretário da Fazenda. No documento consta que:

Trata-se de uma cafetina que tendo aportado nesta cidade, já poude, com o comércio ilícito, adquirir propriedade, sendo elemento prejudicial á sociedade. Ultimamente, por ter esta coletoria exigido o pagamento de impostos atrazados, vem procurando desmoralizar a ação fiscal com cartas anônimas enviadas aos poderes publicos, provocando até a vinda a esta cidade de um emissário secreto para sindicar em torno das acusações por ela levantadas, tendo o referido enviado verificado a improcedência de tais acusações (CMRJU/IMHC/UCS. Indagações Policiais. Processo $n^{\circ} 17$, caixa $n^{\circ} 2$ C:5. 1938).

O interrogatório das testemunhas aconteceu em 31 de março de 1938, quando seis pessoas depuseram contra Cobra. Nos depoimentos, chama a atenção o fato de que, muitas vezes, as reclamações foram direcionadas aos comportamentos de mulheres que, de acordo com as testemunhas, andavam com trajes inadequados e pronunciavam palavras impróprias, e não somente em decorrência do barulho e da violência, produzidos, inclusive, por homens:

[...] a grande gritaria, grande barulho, à noite, no referido estabelecimento, e palavras obscenas proferidas pelas decaídas que não se importam com as famílias que moram vizinhas. De dia, também, aparecem essas mulheres, pelas janelas e fundos do lote, em completo desalinho, quasinúas, provocando cenas imorais de todo o geito (CMRJU/IMHC/UCS. Indagações Policiais. Processo $n^{\circ} 17$, caixa ${ }^{\circ}$ 2C:9. 1938).

O discurso presente nos depoimentos reflete uma construção social que permeia as vivências das mulheres e a percepção dos indivíduos que vivem na sociedade. Logo, tal fala demonstra uma cultura na qual a figura feminina estava entrelaçada a valores determinados socialmente e a um ideário sobre o feminino baseado em uma moralidade rígida referente às mulheres. Conforme Fabiana Oliveira e Virgínia Silva (2005:250): "ao narrar sua interpretação sobre um caso, parece evidente que o depoente estará usando determinadas associações, valores, preconceitos e estigmas e que isto, de algum modo, estará registrado no processo".

No decorrer do processo, é notória a utilização das palavras "sanear" e "limpeza", adquirindo um sentido de solução à imoralidade referida na localização do bordel. Em alguns momentos, foi sugerido pelas testemunhas que Ercília devesse ir para um local mais afastado da cidade, de modo a não mais incomodar os vizinhos. Em um dos depoimentos, a testemunha alega que os moradores daquela região estavam dirigindo um memorial "no sentido de sanearem e moralizarem essa zona da cidade de Caxias" (CMRJU/IMHC/UCS. Indagações Policiais. Processo n ${ }^{\circ} 17$, caixa n ${ }^{\circ} 2 \mathrm{C}: 10$. 1938). Esse memorial pode estar se referindo ao abaixo assinado, já descrito por Mott (1986), o qual teria ocasionado a saída da autora para um local mais afastado e periférico da cidade.

Consequentemente, o ato em questão reflete o processo de higienização da cidade. Sidney Chalhoub (1996) ao discorrer sobre o surgimento da ideologia da higiene no século XIX, explica, por meio das classes sociais, que os pobres ofereceriam problemas para a organização do trabalho $e$ da manutenção da vida pública, uma vez que tal classe, por muito tempo, foi relacionada ao vício de drogas. Além do perigo de furto e de drogadição, o qual se pensava ser proveniente dos pobres, havia a ideia de contaminação. O entendimento acerca perigo de contágio induziu o diagnóstico de que os hábitos de moradias pobres configuravam como nocivos à sociedade, e que as habitações 
coletivas seriam foco de epidemias, além de ser uma propagação de vícios. Como solução para esse problema social, criaram-se práticas higienistas, que, por fim, resultaram no estabelecimento dos

instrumentos legais para a guerra de extermínio contra os cortiços- o que dá quase no mesmopara a política de expulsão das 'classes pobres'/ 'classes perigosas' das áreas centrais da cidade (Chalhoub, 1996:34).

Nesse sentido, a higienização age em torno daquilo que afeta o corpo social, e atenta contra os princípios da civilização e da moralidade (Chalhoub, 1996). No cenário em questão, os prostíbulos também representam uma ameaça. De acordo com Afonso Oliveira Sobrinho (2013), os locais considerados "lacivos e destruidores de lares", como os bordéis, violam a moralidade disseminada pela família burguesa católica. Assim, percebe-se o atravessamento da instituição religiosa nos valores, que influenciavam as ações políticas ligadas à higienização. É importante ressaltar que Caxias do Sul, nesse período, tinha um predomínio significativo da igreja católica como religião central (Favaro, 1996).

A prostituição que se revelava contra os princípios da igreja, da família e do campo social adentra o processo de higienização social, e se apresenta no discurso do denunciante do processo de Cobra:

Pois bem, Caxias, a nossa cidadesinha colonial, está infestada, está cheia de tão indesejáveis e perigosos elementos. A prostituição que por aí campeia, faz questão de, audaciosamente, infiltrar-se no meio das famílias e ambientes familiares, fácto que por certo constitue grave perigo ao meio social, si medidas acuteladoras, urgentes e energéticas, não se fizerem sentir.

[...] na louvável intenção de sanear o centro da cidade dos elementos maus e perigosos, moveram e estão movendo fórte e intransigente campanha contra prostituição, o proxenetismo $e$ a cafetinagem que imperam e devastam zonas centrais em promiscuidade com as famílias. Como medida altamente moralizadora, tais elementos foram expulsos e localizados em postos adequados, longe do contato do meio social (CMRJU/IMHC/UCS. Indagações Policiais. Processo no 17 , caixa $n^{\circ} 2$ C:4. 1938).

A "forte e intransigente campanha", citada acima, corresponde à Campanha pelo Saneamento Moral da Cidade, movida a partir da década de 1930 pelos jornais locais. De acordo com Matté (2008), tal campanha incentivava em seus artigos o afastamento da zona do meretrício do centro da cidade.

Outra questão que se mostra relevante para o entendimento da tentativa dos vizinhos em afastar Cobra do centro da cidade é em relação a sua representatividade em meio ao cerne da família patriarcal e conservadora da sociedade caxiense. Lange (2012:324) explica que a decisão acerca do isolamento de convívio social, baseava-se, também, na "falta de austeridade moral, obediência, sujeição e respeito à hierarquia dos papéis sexuais destinados a homens e mulheres". Com isso, a autora explica que, quando uma mulher assume uma posição diferente daquela esperada pela sociedade, seja de prostituta ou de amante, está representando a "transgressão da excelência da família conjugal e da moral patriarcal" (Lange, 2012:324). Cobra, não era prostituta no bordel (Mott, 1986), mas representou, assim como as demais donas de bordéis, a transgressão da mulher caxiense.

Até o momento, foram encontrados na cidade dois documentos que comprovam que Cobra esteve em Caxias do Sul, pelo menos no início de 1934. O primeiro refere-se ao requerimento enviado à Prefeitura Municipal no mês de abril ${ }^{4}$, no qual, com o pseudônimo Suzana Germane ${ }^{5}$, solicitava que a Prefeitura mandasse que a Diretoria de Obras lhe fornecesse um alinhamento para seu prédio na rua Bento Gonçalves. Cobra, no mesmo ano, desistiu de tal solicitação. E o outro, diz respeito a sua inscrição no livro de impostos da Décima Urbana ${ }^{67}$, no mês de outubro.

\footnotetext{
4 Arquivo Histórico Municipal João Spadari Adami. Requerimento, 03 de abril, 1934.

${ }^{5}$ Nos documentos encontrados, nos quais há menção a esse nome, percebem-se variações em sua forma de escrita.

6 A décima urbana era um imposto, que consistia em uma taxa sobre o valor locativo dos prédios urbanos. Passou por diversas nomenclaturas. Atualmente, aparece como Imposto Predial e Territorial Urbano (IPTU).

7 Arquivo Histórico Municipal João Spadari Adami. Livro Décima Urbana, 1934.
} 
Ao longo dos próximos quatro anos, há pelo menos seis requerimentos que Cobra enviou à prefeitura, em alguns dos quais solicitava licença para realizar instalações sanitárias no prédio, além de reclamar sobre as condições da rua. ${ }^{8}$ Dentre esses, encontram-se também, outros dois ${ }^{9}$ nos quais Cobra teria solicitado para quitar os impostos provenientes da Décima Urbana, no decorrer do ano de 1937, que já estava em dívida ativa, e, no ano de 1938, que a Prefeitura parcelasse sua dívida sobre os impostos de policiamento e música. Este último fora negado.

Tais requerimentos dão indícios de suas dificuldades financeiras e vão ao encontro do documento, encontrado no IMHC, que diz respeito a um processo do Executivo Fiscal ${ }^{10}$ movido pela Prefeitura Municipal contra Cobra, o qual apresenta os primeiros indícios do tempo total em que Cobra viveu na cidade. O processo é movido no dia 10 de julho do ano de 1939, devido ao não pagamento dos impostos referentes a água, taxa de policiamento, sala de bailes e aferição de pesos e medidas, resultando no valor de dois contos e cinquenta e dois mil réis, referentes aos anos de 1936, 1937 e 1938. Nesse documento, consta que Cobra não estava mais na residência, e seria possível que estivesse em São Leopoldo.

Assim como os processos judiciais, a imprensa regional representa um importante resgate do passado e das histórias. É por meio dos jornais da década de 1930 que, também, se torna possível acompanhar o andamento do caso. Encontrou-se um anúncio de venda de um piano alemão e de uma rádio-eletrola, no Jornal $O$ Momento $^{11}$, no ano de 1939, indicando Suzi como vendedora. Isso apresenta indícios de que Cobra tenha anunciado seus objetos, estando localizada em outra pensão da cidade, denominada Pensão Angela ${ }^{12}$, estabelecida na Avenida Júlio de Castilhos. Outro indício que aponta que a rádio-eletrola e o piano estavam sendo vendidos por ela é a menção da compra do instrumento em uma das cartas enviadas à irmã, revelada por Mott (1986).

Esses aspectos trazidos acerca do atraso do pagamento dos impostos e das vendas dos objetos podem ser resultado das dificuldades financeiras enfrentadas pela autora nesse período. Mott (1986) revela que Cobra teria pedido um empréstimo, e que a carta que enviou à irmã, apresentando a nota da compra do rádio, deu-se com o intuito de que a irmã soubesse sobre seus bens.

Uma vez que não houve o pagamento das dívidas, por meio do Decreto-lei $\mathrm{n}^{\circ} 960$ de 17 de dezembro de 1938, art 6, 13, 14 e 15, o Município levou a propriedade à hasta pública. No mês de junho de 1940, o Jornal A E'poca ${ }^{13}$ lançou os primeiros editais de penhora da casa para pagamento de impostos, alegando, também, que a autora "encontrava-se em lugar incerto e não sabido". No mês de setembro do mesmo ano, o imóvel foi levado à praça:

Faz saber aos que o presente edital virem, ou dele tiverem conhecimento, que designou o dia dezenove de Setembro próximo vindouro, às quatorze horas, no edifício do Fórum, sala número onze, para hasta pública de venda e arrematação do seguinte imóvel, penhorado à Ercília Nogueira Cobra, no executivo fiscal que lhe move a Prefeitura de Caxias: um lote de terras com quinze metros de frente por quarenta e quatro de fundos, contendo uma casa construída de madeira, coberta com telhados de barro e outras benfeitorias,[...]. (A É'POCA. Caxias do Sul: Edital de $1^{a}$ Praça, 7 de setembro, [s.p], 1940)

Os próximos relatos na imprensa aparecerão dois anos depois, em 1942, com o Edital de $2^{\text {a }}$ Praça, no Jornal $O$ Momento $^{14}$, mas somente anunciando a penhora de parte do terreno, sem mais citar a residência. Essa demora para o lançamento do edital é esclarecida no Processo de Executivo Fiscal, ocorrendo devido a outra ação executiva movida contra Cobra, porém, dessa vez, pela Fazenda do Estado, também referente a dívidas ativas de impostos. A situação causou divergências entre o Estado e o Município, pois a Prefeitura não poderia penhorar um bem que já havia sido

\footnotetext{
8 Esses requerimentos correspondem respectivamente a abril de 1935 e maio de 1938.

9 Arquivo Histórico Municipal João Spadari Adami. Requerimento, 07 de julho, 1937.Arquivo Histórico Municipal João Spadari Adami. Requerimento, 09 de maio, 1938.

${ }^{10}$ CMRJU/IMHC/UCS. Executivo Fiscal. Processo nº 07, caixa 09B, V.1. 1939.

${ }^{11}$ O MOMENTO. Caxias do Sul, 13 de fevereiro. 1939.

${ }^{12}$ CMRJU/IMHC/. Processo nº 02, caixa 13D. 1942.

${ }^{13}$ A E'POCA. Caxias do Sul: Edital de $1^{\text {a }}$ Praça, 16 de junho. 1940.

${ }^{14}$ O MOMENTO. Caxias do Sul: Edital de 2a Praça, 15 de julho. 1942
} 
objeto de penhora. E, nesse caso, a Fazenda do Estado tinha preferência sobre a penhora do Município. Após um acordo, não especificado nesse documento, com a venda e demolição da casa, quitou-se a dívida com o Estado, e a penhora do lote, ocorrida em 10 de julho de 1942, cobriu a dívida com o Município, restando, somente, os impostos relacionados a Indústrias e Profissões.

Descobriu-se por meio de requerimentos que Cobra enviou à Prefeitura, no ano de $1940^{15}$, que a demolição da residência foi requisitada por ela mesma, por essa se encontrar em estado precário, e, também, como uma forma de interromper os impostos e juros. No requerimento, assinado pelo seu procurador Pedro Marques Vianna, consta o seguinte:

ERCÍLIA NOGUEIRA COBRA, por seu procurador abaixo assinado, vem, mui respeitosamente requerer a $\mathrm{V}$. S. se digne de mandar dar baixa de todos os impostos e taxas que onerem o prédio de sua propriedade sito nésta cidade, à rua Bento Gonçalves, $\mathrm{n}^{\circ} 1760 \mathrm{em}$ virtude de estar o mesmo desocupado há muito tempo, cerca de um ano, e ser já muito velho e inabitável. A baixa requerida refere-se ao ano em curso. Requér mais, o fornecimento de uma licença para a demolição do referido prédio, cujo madeiramento já está sendo negociado (Requerimento, 20 de outubro, 1940).

A prefeitura solicitou as provas de que Pedro Marques Vianna fosse realmente o procurador de Cobra. Então, no dia 11 de novembro do mesmo ano, o procurador envia outro requerimento ${ }^{16}$ solicitando, novamente, a baixa dos impostos e a demolição da casa, porém com novo detalhe: o procurador revela que haveria a venda do respectivo madeiramento, "conforme entendimento verbal com Dr. Procurador dessa Prefeitura" (Requerimento, 11 de novembro, de 1940). Isso permite o esclarecimento de que o acordo citado no processo se deu entre Cobra e a Fazenda Estadual, assim, o dinheiro arrecadado com a venda das madeiras liquidou a dívida com órgão.

O último registro oficial, até então encontrado, de que a autora estava na cidade de Caxias do Sul, diz respeito ao ano de 1942, quando Cobra quitou a dívida que ainda tinha com a Exatoria Estadual referente aos Impostos de Indústria e Profissões dos anos de 1937 e 1938. Documentações de 14 de julho de 1942 comprovam que a autora nada deve à Fazenda Estadual, nem à Prefeitura do Município de Caxias do Sul:

Ercilia Nogueira Cobra, vai a Exatoria desta cidade, pagar a quantia de três contos trezentos $e$ trinta e nove mil seiscentos, referente a sua dívida ativa do imposto de Indústria e Profissões 1937 e 1938, e respectivamente adicionais descriminados.

[...] os bens estão quites perante a Fazenda Municipal, quanto ao pagamento de quaisquer imposto ou taxa (CMRJU/IMHC/UCS. Executivo Fiscal. Processo 07, caixa 09B, vol.1,pp.6364. 1939).

Dessa maneira, verifica-se que Ercília Nogueira Cobra, ainda que tenha tido uma vida bastante tumultuada na cidade, conseguiu resolver seus problemas com a Prefeitura, quitando suas dívidas com a sociedade caxiense.

\section{Considerações finais}

O estudo realizado contempla um recorte da vida da autora Ercília Nogueira Cobra na cidade de colonização italiana Caxias do Sul, no estado do Rio Grande do Sul, evidenciando os achados até o momento. Neles, incluem-se processos judiciais, artigos de jornais e requerimentos enviados à Prefeitura da cidade, os quais contribuíram de modo significativo para o entendimento da trajetória da escritora na cidade gaúcha. Os registros apontam que sua estadia na cidade iniciou em 1934, permanecendo até 1939. No entanto, um último registro demonstra que Cobra esteve na cidade no ano de 1942 ou pelo menos em locais próximos. Portanto, sua permanência na região durou cerca de 8 anos.

\footnotetext{
${ }^{15}$ Arquivo Histórico Municipal João Spadari Adami. Requerimento, 20 de outubro. 1940.

${ }^{16}$ Arquivo Histórico Municipal João Spadari Adami. Requerimento, 11 de novembro. 1940.
} 
Na trajetória da autora, é possível deparar-se com uma série de restrições que sofreu ao longo de sua vida. Em um primeiro momento é detida em um asilo, cujo objetivo era educar moças; logo a proibição de seus livros, e depois, o interrogatório pelo Estado Novo. Essa realidade não foi diferente na cidade de Caxias do Sul. Cobra vivenciou a interdição por processos judiciais, o que refletiu em sua relação com a sociedade caxiense.

Apesar de que, na década de 1930, houvesse uma grande demanda de trabalho feminino dentro das fábricas, Cobra não se submeteu a ele. Pelo contrário, escolheu um ramo no qual, de certo modo, poderia exercer sua autonomia e independência. Permanecendo no campo das mulheres marginalizadas, com atitudes audaciosas e com comportamentos que contrastaram com a figura feminina idealizada, Ercilia representou a transgressão de sua condição de mulher, e isso resultou, de certa forma, no processo executado contra ela. A sua relação com sociedade caxiense é marcada, também, por suas dificuldades financeiras, que, juntamente com a rejeição ao seu modo de viver, ocasionaram ações da ordem higienizadora, o que pode ter acarretando sua saída da cidade.

As narrativas presentes no processo contra a Pensão Royal evidenciam o atravessamento daquilo que Cobra, em suas obras, denominou de dupla moralidade. Por um lado, o discurso queixava-se da violência e desordem ocasionada no cabaré, mencionando a conduta masculina; do outro, porém, e de modo proeminente, a denúncia das condutas femininas que fogem aos padrões morais.

Embora, atualmente, pesquisadores da cidade tenham voltado seus olhares para a trajetória de Cobra, essa é tampouco lembrada, permanecendo ainda no silenciamento. Quando muito, é lembrada pela cidade como uma dona de cabaré, jamais reconhecida por ser escritora.

Ao findar tais investigações percebe-se a importância do resgate dessa vivência, que dificilmente cessará nessa pesquisa. Uma vez que a vida da escritora Ercília Nogueira Cobra ainda necessita ser explorada, novas pesquisas envolvendo sua trajetória poderão influenciar o interesse de pesquisadores, visto que suas obras apresentam um significativo e indispensável material histórico e sociológico.

\section{Referências bibliográficas}

BIBLIOTECA NACIONAL DIGITAL: Hemeroteca Digital [http://bndigital.bn.gov.br/hemeroteca-digital/acesso em: 24 jan. 2019].

BRASIL. Decreto-lei $n^{\circ}$ 960, de 17 de dezembro de 1938 [http://www.planalto.gov.br/ccivil_03/decretoLei/1937-1946/Del0960.htm - acesso em: 18 dez. 2018].

CENTRO DE MEMÓRIA DA CÂMARA MUNICIPAL DE CAXIAS DO SUL [http://liquid.camaracaxias.rs.gov.br/portalliquid/Pesquisa/Index/3 - acesso em: 13 fev. 2019].

CHALHOUB, Sidney. Cidade febril: cortiços e epidemias na corte Imperial. São Paulo, Companhia das Letras, 1996.

CMRJU/IMHC/UCS. Indagações Policiais. Processo 17, caixa n² 2C. 1938.

CMRJU/IMHC/UCS. Executivo Fiscal. Processo 07, caixa 09B, v.1. 1939.

DA CANAL, Sandra; WENCZENOVICZ, Thaís Janaina. Máscaras do corpo: do costume à moral. Passo Fundo, Méritos, 2012.

DOTTI, Gabriela Michelon. Representações do feminino de tradição oral da RCI: o que se diz sobre a mulher. 2007. Dissertação (Mestrado em Letras e Cultura Regional) - Universidade de Caxias do Sul, 2007.

FAVARO, Cleci Eulalia. Mulher, sinônimo de trabalho: papéis sociais, imaginários e identidade feminina na Região Colonial Italiana do Rio Grande do Sul. Estudos Ibero-Americanos, n. 2, Porto Alegre, dez. 1996, pp.211-229.

GIRON, Loraine Slomp. O Som do Silêncio: sexo e prostituição na colônia. Coletânea Cultura e Saber/UCS, Caxias do Sul, n.2, v. 3, 1999, pp.117-134.

LANGE, Daysi. Amasias, esposas e prostitutas: da situação de vítimas ao papel de transgressoras. Métis: história \& cultura, n. 21, vol. 11, Caxias do Sul, jan/jun. 2012, pp.315-326. 
LAZZAROTTO, Valentim. Pobres construtores de riqueza. Caxias do Sul, EDUCS, 1981.

IOTTI, Luiza Horn; GOMES, Fabrício Romani. Centro de Memória Regional do Judiciário: possibilitando pesquisas e preservando a história de Caxias do Sul/RS. Métis: história \& cultura, n. 21, v. 11, Caxias do Sul, jan./jun. 2012, pp.101-114.

MACHADO, Maria Abel. Mulheres sem rosto. Caxias do Sul, RS, Maneco, 1998.

MATTÉ, Aline Karen. Prazeres velados e silêncio suspirados: sexualidade e contravenções na Região de Colonização Italiana (1920-1950). Dissertação (Mestrado em História) - Pontifícia Universidade Católica do Rio Grande do Sul, 2008.

MOTT, Maria Lúcia de Barros. Biografia de uma revoltada: Ercília Nogueira Cobra. Caderno de Pesquisa, n. 58, São Paulo, ago. 1986, pp.89-104.

OLIVEIRA, Fabiana Luci de; SILVA, Virgínia Ferreira. Processos judiciais como fonte de dados: poder e interpretação. Sociologias, n. 13, Porto Alegre, jan./jun. 2005, pp.244-259 [https://www.redalyc.org/pdf/868/86819561010.pdf- acesso em: 02 fev. 2019].

OLIVEIRA SOBRINHO, Afonso Soares de. São Paulo e a Ideologia Higienista entre os séculos XIX e XX: a utopia da civilidade. Sociologias, n. 32, Porto Alegre, jan./abr. 2013, pp.210-235 [https://www.scielo.br/scielo.php?pid=S1517-45222013000100009\&script=sci_abstract\&tlng=PT acesso em: 25 jan. 2019].

RAGO, Margareth. Do cabaré ao lar: a utopia da cidade disciplinar, Brasil 1900-1930. Rio de Janeiro, Paz e Terra, 1997.

SOUSA, Danielle de Medeiros. O grito do silêncio na obra de Ercília Nogueira Cobra: de mulher demoníaca a feminista pioneira. Dissertação (Mestrado em Ciências Sociais) - Universidade Federal do Rio Grande do Norte, 2016. 